Article

\title{
A Green Process for the Extraction and Purification of Hesperidin from Mexican Lime Peel (Citrus aurantifolia Swingle) that is Extendible to the Citrus Genus
}

\author{
J. Daniel Padilla de la Rosa ${ }^{1}$, Priscilla Ruiz-Palomino ${ }^{1, *}$, Enrique Arriola-Guevara ${ }^{2}$, \\ Jorge García-Fajardo ${ }^{1}$, Georgina Sandoval ${ }^{1}$ (D) and Guadalupe M. Guatemala-Morales ${ }^{1, *(D)}$ \\ 1 Tecnología Alimentaria, Biotecnología Industrial, Centro de Investigación y Asistencia en Tecnología y \\ Diseño del Estado de Jalisco, A.C., Normalistas 800, C.P. 44270, Guadalajara, Jalisco, Mexico; \\ jdpadilla@ciatej.mx (J.D.P.d.l.R.); jgarcia@ciatej.mx (J.G.-F.); gsandoval@ciatej.mx (G.S.) \\ 2 Departamento de Ingeniería Química, Centro Universitario de Ciencias Exactas e Ingenierías, \\ Universidad de Guadalajara. Blvd. Marcelino García Barragán \#1421, esq. Calzada Olímpica. C.P. 44430, \\ Guadalajara, Jalisco, Mexico; enrique.arriola@academicos.udg.mx \\ * Correspondence: prruiz_al@ciatej.edu.mx (P.R.-P.); gguatemala@ciatej.mx (G.M.G.-M.); \\ Tel.: +33-33455200 (ext. 1501) (G.M.G.-M.)
}

Received: 13 November 2018; Accepted: 11 December 2018; Published: 15 December 2018

\begin{abstract}
The processing of Mexican limes generates great amounts of peel as a by-product. Lime peel is mainly rich in the flavonoid hesperidin, whose bioactivity is oriented mainly to cardiovascular diseases and cancer. The purpose of this work was to develop a green process for the extraction and purification of hesperidin from Mexican lime peel. The extraction of hesperidin was investigated on a laboratory scale by varying the solvent composition and the solid-to-solvent ratio, and then scaling this process (volume: $20 \mathrm{~L}$ ). Next, a purification process using adsorption resins was assessed: first through static tests to determine the adsorption efficiency with two resins (FPX66, EXA118), and then on a packed column with $80 \mathrm{~mL}$ of resin at $25^{\circ} \mathrm{C}$. Lab-scale extraction showed that the best conditions were a solid-to-solvent ratio of $0.33 \mathrm{~g} / \mathrm{mL}$ and $60 \%$ ethanol. After using these conditions at pilot scale and concentrating the solution, the hesperidin content of the extract was $0.303 \mathrm{mg} / \mathrm{mL}$. Through static tests, higher adsorption efficiencies were achieved with the EXA-118 resin and diluted extract (4:6 ratio with 10\% dimethylsulfoxide, (DMSO)). Finally, the purification process on a packed column from the diluted extract (hesperidin concentration of $0.109 \mathrm{mg} / \mathrm{mL}$ ) had a mean recovery efficiency of almost $90 \%$.
\end{abstract}

Keywords: Citrus aurantifolia Swingle; hesperidin; citrus byproducts; adsorption

\section{Introduction}

The Citrus genus is the most important fruit tree crop in the world, with an annual production of approximately 133 million tons, which consists of oranges (73.2 million tons), tangerines and mandarins (32.8 million tons), lemons and limes (17.3 million tons), and grapefruit (8.4 million tons). These fruit have a high commercial value in both the fresh market and food industry [1,2].

The focus of the citrus processing industry has been the production of juices and essential oils. Approximately $33 \%$ of the citrus production in the world is used for the juice industry, and at least $50 \%$ of the whole fruit mass is residue. Therefore, considering these facts, the worldwide estimate of lime peel residue is 2.8 million tons per year. Clearly, this huge amount of generated citrus waste should be managed and industrialized properly, since it tends to constitute a severe environmental problem [2]. 
An attempt to reclaim some value from the residues generated by the citrus processing industry is to identify and extract the bioactive compounds within the residues. Citrus peel has a high content of flavonoids, and the flavanone glycoside hesperidin, is the most abundant [3] (Figure 1). The content of this flavonoid in the tissues of Mexican lime is in the order of $197 \mathrm{mg} / 100 \mathrm{~g}$ of fresh tissue [4].

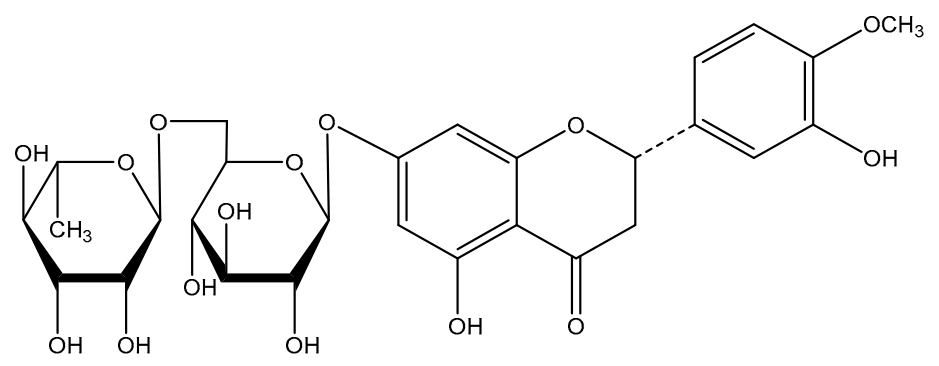

Figure 1. Chemical structure of hesperidin, figure adapted from [5].

Hesperidin (3',5,7-trihydroxy-4'-methoxy-flavanone-7-rhamnoglucoside) exhibits multiple biological properties: antioxidant, anti-inflammatory [6], antihypercholesterolemic [7], anti-hypertensive, anticarcinogenic, antimicrobial, and antiallergenic. It is neuroprotective, and it has vasodilator and diuretic properties [8-10]. This flavonoid is also important in the pharmaceutical, cosmetic, and food and beverages industries.

Traditionally, hesperidin has been obtained from the citrus peel by using alkaline extraction. First of all, the peel is ground and washed to remove soluble solids, then it is blended with a water and $\mathrm{NaOH}$ solution ( $\mathrm{pH}$ 11-11.5). After $1 \mathrm{~h}$ at room temperature, the insoluble solids are separated and the liquid phase is filtered. Mineral acids are then added to the filtered product to change the $\mathrm{pH}$ to $4.2-4.5$, and the solution is heated at $40-45^{\circ} \mathrm{C}$ for $12-24 \mathrm{~h}$. The hesperidin crystals formed that way are separated and dried. Generally, this procedure allows for the formation of a flavonoid complex, which has $60-70 \%$ hesperidin content. To obtain a higher hesperidin content $(>95 \%)$, repeated crystallizations can be done [11]. As expected, this process is time-consuming, and it requires a significant amount of acids and bases. In addition, other compounds are simultaneously extracted, resulting in reduced efficiency and purity.

An alternative for the alkaline extraction method is the use of organic solvents. While methanol is an effective solvent for hesperidin extraction, its toxicity limits its application. Ethanol is a substitute that is used as a solvent in the food industry. It has been proven to be useful in the extraction of phenolic compounds in some citrus products [12,13]. In addition, ethanol is thought of as a bio-solvent, because it can be produced from renewable resources [14]. The extraction process by itself presents low selectivity, and further purification of the required compound is thus necessary.

One of the most commonly used processes for flavonoid purification from extracts is resin adsorption. The alkaline treatment of peels and wastewater, coupled with the resin adsorption (styrene-divinylbenzene resins) step to obtain a more concentrated solution, which leads to more rapid crystallization, has been previously reported $[15,16]$; the recovery efficiencies in these studies were $64 \%$ from waste water and over $90 \%$ from orange peels. Additionally, the adsorption of hesperidin in 13 resins has been evaluated using model hesperidin solutions. Resin EXA-118, which has a high surface area, was most effective [17].

Amberlite FPX66 can also be used for a wide variety of food processing applications to both recover high value materials and to purify and decolorize food and food additive streams. Resin FPX66 is a macroreticular, non-functionalized adsorbent resin designed for the juice processing market, where local regulations allow for such use. This resin has been used to purify hesperidin from hydroalcoholic extracts of Persian lime peel, achieving a recovery efficiency of $80 \%[18,19]$.

Moreover, not many studies exist on the extraction and purification of hesperidin from Mexican lime, because most studies are focused mainly in the purification of hesperidin from orange (Citrus sinensis). For that reason, the objective of this present study was to evaluate a green, simple, 
and economic alternative for the production of hesperidin from citrus peel. The process includes the hydroalcoholic extraction of hesperidin from Mexican lime peel and further purification using adsorption resins to increase recovery efficiency.

\section{Materials and Methods}

Mexican lime fruits, which originated from the region of Tecomán, Colima, México, were purchased at a local market (Mercado de Abastos, Guadalajara, Jalisco, México) in February 2016. Standard hesperidin was purchased from Sigma-Aldrich (purity $>90 \%$, Saint Louis, MO, USA). The ethanol for extraction had a purity of $96 \%$, and the dimethylsulfoxide (DMSO) had a purity of $90 \%$ (Karal, León, Guanajuato, México). The solvents that used for analysis were of chromatography grade. The resins used were Relite EXA118 (Resindion, Binasco, Milan, Italy) and Amberlite ${ }^{\text {TM }}$ FPX66 (Rohm and Haas, Philadelphia, PA, USA).

\subsection{Hesperidin Content}

To quantify flavonoids in citrus peels, the total hesperidin content in the Mexican lime peel was determined based on the procedure proposed by Nogata et al. (2006). Three limes were squeezed, and $1 \mathrm{~g}$ of peel was taken from each. Each sample was dried at $70^{\circ} \mathrm{C}$ in a moisture analyzer (MF-50, A\&D, Milpitas, CA, USA), and ground in a mortar. Next, $100 \mathrm{mg}$ of each sample were placed in individual test tubes, where three consecutive 24-h extractions were performed (static maceration at room temperature, under dark conditions). Each extraction was done with $1.5 \mathrm{~mL}$ of a 1:1 $(v / v)$ solution of methanol and DMSO. The three extracts were combined, and the concentration of hesperidin was determined by high performance liquid chromatography (HPLC).

\subsection{Extraction}

\subsubsection{Lab-Scale Extraction}

There are many factors that affect extraction yield, such as the effect of repeated extraction, solvent type and volume, temperature, and sample characteristics (shape and particle size) [13]. In this work, we chose to study the solid-to-solvent ratio and the solvent composition. The remaining operating conditions were selected based on previous studies of hesperidin extraction from Persian lime peel $[18,19]$.

Extraction was performed in $250 \mathrm{~mL}$ Erlenmeyer flasks, at $50{ }^{\circ} \mathrm{C}$ for $4 \mathrm{~h}$, with $120 \mathrm{rpm}$ agitation in an orbital shaking incubator (G25, New Brunswick, Edison, NJ, USA). Fresh peel was used as the extraction material, and the solvent volume was $50 \mathrm{~mL}$. At this stage of the process, $2 \mathrm{~kg}$ of Mexican limes were washed to remove impurities. They were then squeezed, and the seeds were manually removed. Finally, the peel was ground up in a blender (LM313A28, Moulinex, Millville, NJ, USA), until the particle size was less than $1 \mathrm{~cm}$.

The solid-to-solvent ratio and the solvent composition were varied according to the $2^{3}$ experimental design (with two central points), and they were duplicated. The central points were added to observe the linearity of the response variable. The controlled variables were the percentage ethanol in the solvent $(0,60)$, the percentage DMSO in the solvent $(0,20)$ and the solid-to-solvent ratio in $\mathrm{g} / \mathrm{mL}$ $(0.1,0.33)$. The response variables were the concentration of hesperidin in the extract, and the extraction yield. In Table 2, the required amount of lime peels (for $50 \mathrm{~mL}$ of solvent), DMSO, and ethanol are specified for each run of the experimental design. The remaining percentage of the solvent was distilled water.

The use of DMSO was proposed because hesperidin has processing difficulties, due to its low solubility in water $(<20 \mathrm{mg} / \mathrm{L})$ [20]. Its solubility is greatly increased in DMSO, at a concentration of $122 \mathrm{mg} / \mathrm{mL}$ [21]. DMSO is considered to be a green solvent, and it is one of the least toxic organic chemicals known [22]. Because it has low chronic and acute oral toxicity, it offers a delivery option for difficult-to-dissolve medications [23]. 
The extracts were separated from the exhausted solids with a strainer, and stored at $8{ }^{\circ} \mathrm{C}$ in amber containers. The concentration of hesperidin in the extracts was determined by HPLC, and the yields were calculated. Statistical analysis was conducted with STATGRAPHICS Centurion®software (Version XVI, Statgraphics Technologies Inc., The Plains, VA, USA).

\subsubsection{Pilot-Scale Extraction}

The same conditions that were selected from the lab-scale extraction stage were used in the pilot scale. Waxes and impurities were eliminated by washing $50 \mathrm{~kg}$ of Mexican limes with water. Next, the fruits were fed to a screw press operated at a frequency of $30.0 \mathrm{~Hz}$, to separate the juice and some of the seeds from the peel. The remaining seeds were removed manually. The peel was ground in an industrial blender with a 5 L capacity (Veca International, Nezahualcóyotl, México, México) until the particle size was smaller than $1 \mathrm{~cm}$. The juice and the seeds were reserved in refrigeration for other research work. Three extractions were made on the peel. Each extraction was performed using $20 \mathrm{~L}$ of solvent for $3 \mathrm{hr}$ at $50{ }^{\circ} \mathrm{C}$. A pilot extraction tank with stirring and temperature control was used. The extracts from each run were combined and filtered through a $1 \mu \mathrm{m}$ polypropylene cartridge in a filtration unit (Labmaster, Serfilco, Mississauga, ON, Canada). Finally, the extract was concentrated in a rotavapor (R-220, Büchi, New Castle, DE, USA) at $45^{\circ} \mathrm{C}$ and $500 \mathrm{mmHg}$. The filtered and concentrated extract was refrigerated at $8^{\circ} \mathrm{C}$.

\subsection{Purification}

Resins FPX66 and EXA-118 were chosen to evaluate their capacities to adsorb hesperidin from the extract. The resins were activated by an overnight treatment with two bed volumes (BV) of $96 \%$ ethanol, and then were rinsed with $5 \mathrm{BV}$ of deionized water before use. Once pretreated, the moisture content of the resins was determined in a moisture analyzer (MF-50, A\&D, Milpitas, CA, USA) at $70{ }^{\circ} \mathrm{C}$ (for dry weight calculations). To improve the solubility of hesperidin, and to ensure a homogeneous distribution of the solution, $10 \%$ DMSO was added to the extract.

\subsubsection{Static Tests}

\section{Adsorption Kinetics}

The concentration of hesperidin in batch tests was monitored to evaluate the time for adsorption equilibrium. Adsorption was performed by adding $1.7 \mathrm{~g}$ of resin (dry weight) to $50 \mathrm{~mL}$ of extract in a flask at $25^{\circ} \mathrm{C}$. The mixture was stirred at $150 \mathrm{rpm}$ in an orbital shaker (G10, New Brunswick, Edison, NJ, USA) for $5 \mathrm{~h}$. Samples of the extract (1 mL each) were taken at $0,20,40,60,90,120$, 180,240 , and $300 \mathrm{~min}$, and they were analyzed for total flavonoids (see Section 2.5). The analysis for total flavonoids was chosen because the test comprises of a simple colorimetric method, and because hesperidin accounts for most of the flavonoids present in the extract.

\section{Adsorption Efficiency}

A multifactorial experimental design $(6 \times 2 \times 2)$ was used to evaluate adsorption efficiency. The experiments were performed in duplicate. The variables were the resin type (FPX66 and EXA-118), the temperature $\left(25\right.$ and $40^{\circ} \mathrm{C}$ ), and the initial concentration of hesperidin (six levels, where the extract was diluted with the $10 \%$ DMSO solution).

Adsorption was performed by adding $1 \mathrm{~g}$ of resin (dry weight) to $30 \mathrm{~mL}$ of extract in a flask. The temperature was $25^{\circ} \mathrm{C}$, and mixture was stirred at $150 \mathrm{rpm}$ in an orbital shaker (G25, New Brunswick, Edison, NJ, USA) for $3 \mathrm{~h}$. The final concentration was measured by HPLC, and the results were analyzed using the variance analysis with the Statgraphics Centurion ${ }^{\circledR}$ software (Version XVI, Statgraphics Technologies Inc., The Plains, VA, USA). 


\subsubsection{Dynamic Tests}

A fixed bed with $80 \mathrm{~mL}$ of resin was used to evaluate the dynamic adsorption and desorption of hesperidin from the diluted extract of Mexican lime peel. The temperature, initial hesperidin concentration (dilution), and resin were selected from the static tests. Ascending flow was used, and this was done for both operations. The purification operation was performed in cycles comprising the following steps [19]:

1. First wash: The column was washed with $1 \mathrm{~L}$ of deionized water $(5 \mathrm{~mL} / \mathrm{min})$.

2. Adsorption: $1 \mathrm{~L}$ of diluted extract was passed through the column $(5 \mathrm{~mL} / \mathrm{min})$. Samples at $25 \mathrm{~mL}, 50 \mathrm{~mL}$, and $100 \mathrm{~mL}$ were collected at the exit of the column, until the whole volume had been treated.

3. Second wash: The column was washed with $250 \mathrm{~mL}$ of deionized water $(5 \mathrm{~mL} / \mathrm{min})$ to remove any remaining extract (water does not desorb the hesperidin from the column).

4. Desorption: $1 \mathrm{~L}$ of ethanol $96 \%$ was passed through the column $(2.7 \mathrm{~mL} / \mathrm{min})$ to recover the adsorbed hesperidin. Samples at $50 \mathrm{~mL}$ and $100 \mathrm{~mL}$ were collected until there was no volume of ethanol left in the column.

The evaluation of the purification process consisted of three complete cycles. All of the collected samples were analyzed by HPLC.

\subsection{HPLC Analysis}

High performance liquid chromatography (HPLC) was used to determine hesperidin content in all of the samples. Each sample was filtered with a $0.45 \mu \mathrm{m}$ syringe filter, and $10 \mu \mathrm{L}$ was injected into the unit. The chromatograph was a Varian ProStar 420 AutoSampler (Walnut Creek, CA, USA), and the column used was a Phenomenex Gemini ${ }^{\circledR C} 6$-phenyl $150 \times 4.5(5 \mu \mathrm{m})$ (Torrance, CA, USA). Isocratic elution mode with a flow rate of $1 \mathrm{~mL} / \mathrm{min}$ was used, where the mobile phase consisted of water (40\% acidified with $0.1 \%$ acetic acid) and methanol (60\%). The equilibrium time was $3 \mathrm{~min}$, and the analysis time was $7 \mathrm{~min}$. Identification was done with a UV detector at $280 \mathrm{~nm}$. All solvents were filtered through a $0.45 \mu \mathrm{m}$ membrane and sonicated for $20 \mathrm{~min}$. The linear range from the method was 0 to $0.15 \mathrm{mM}(0.0916 \mathrm{mg} / \mathrm{mL})$ of hesperidin, with an $\mathrm{R}^{2}$ of the calibration curve of 0.9989 . The limit of detection (LOD) and the limit of quantification (LOQ) of the method were, $0.0087 \mathrm{mg} / \mathrm{mL}$ and $0.0264 \mathrm{mg} / \mathrm{mL}$, respectively.

\subsection{Total Flavonoids}

A total flavonoids colorimetric method was used to observe the equilibrium time in the adsorption kinetic test. It consisted of taking $250 \mu \mathrm{L}$ of the extract sample and diluting it in $1.25 \mathrm{~mL}$ of distilled water. Next, $75 \mu \mathrm{L}$ of $5 \% \mathrm{NaNO}_{2}$ solution was added, and the sample was left to stand for $6 \mathrm{~min}$. Subsequently, $150 \mu \mathrm{L}$ of $1 \mathrm{M} \mathrm{NaOH}$ solution and $775 \mu \mathrm{L}$ of distilled water were added to obtain a final volume of $3 \mathrm{~mL}$. The sample was stirred in a vortex mixer for 10 seconds, and the absorbance was immediately measured at $510 \mathrm{~nm}$ in a UV-Vis spectrophotometer (Genesys 10S, Thermo Scientific, Madison, WI, USA) [24].

\section{Results and Discussion}

\subsection{Hesperidin Content}

Three limes were randomly selected, and a fraction of their peels was dried. The total hesperidin content was determined by extraction using a mixture of 50\% ethanol and 50\% DMSO. The average concentration of the extracts, moisture content and dry and wet weight calculations are shown in Table 1 (quantified by HPLC). 
Table 1. Total hesperidin content in Mexican lime peel.

\begin{tabular}{ccc}
\hline Parameter & Mean Value & Variation Coefficient (\%) \\
\hline Extract concentration $(\mathrm{mg} / \mathrm{mL})$ & $0.078 \pm 0.021$ & $33.4 \%$ \\
Dry peel concentration $(\mathrm{mg} / \mathrm{g})$ & $3.528 \pm 0.962$ & $33.4 \%$ \\
Moisture content $(\%)$ & $81.57 \pm 1.92$ & $2.9 \%$ \\
Fresh peel concentration $(\mathrm{mg} / \mathrm{g})$ & $0.653 \pm 0.208$ & $39.1 \%$ \\
\hline
\end{tabular}

Nogata et al. [4] have reported a content of $1.97 \mathrm{mg} / \mathrm{g}$ in the fresh peel of Citrus aurantifolia Swingle. By comparison, we obtained a substantially lower mean concentration of $0.65 \mathrm{mg} / \mathrm{g}$. Moisture content was not reported by Nogata et al. [4], and this could be a source of the discrepancy among the results. However, the average moisture content found in this work was similar to previous reports of Mexican lime peel [25]. These findings indicate that other important differences can be observed among fruit of the same species. Factors such as growing conditions (e.g., weather, soil type and irrigation), harvest time, storage conditions, and size influence the flavonoid content, which subsequently hinders the appropriate contrast of the results obtained in each study [26,27]. Looking at the variation coefficients among measurements in Table 1, these factors can also be the reason behind the variability among samples, which was high for concentration values and low for moisture content.

\subsection{Extraction}

\subsubsection{Lab-Scale Extraction}

The main objective was to implement a green process to recover the hesperidin content in citrus peels. The first stage of the selected process was the solvent extraction. This is because prior to the adsorption process, it is possible (and highly desired) to eliminate the solvent from the extract by evaporation, to recover the solvent, and to reuse it in the extraction step. The first step was to evaluate (at lab-scale) the influence of the solid-to-solvent ratio and the solvent composition over two response variables: the concentration of hesperidin in the extract and the extraction yield.

The behavior of the first response variable is depicted in Figure 2. The variance analysis proven that the three studied factors significantly affected $(p<0.05)$ the content of hesperidin in the extracts.

A

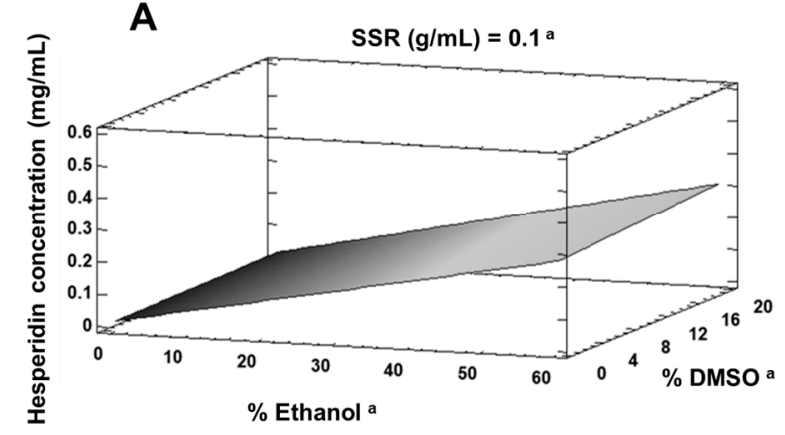

B

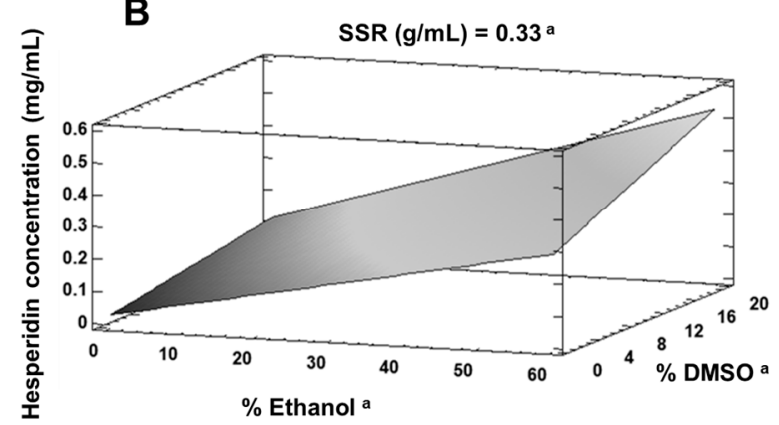

Figure 2. Concentration of hesperidin in the extract for a solid-to-solvent ratio (SSR) of $0.1 \mathrm{~g} / \mathrm{mL}$ (A) and $0.33 \mathrm{~g} / \mathrm{mL}(\mathbf{B}){ }^{a}$ Significant factors in the variance analysis $(p<0.05)$.

The interaction between the solvent-to-solid ratio (SSR) and the DMSO percentage was also significant. It can be noted from Figure 2 that higher levels of the three factors (SSR $=0.33 \mathrm{~g} / \mathrm{mL}$, $60 \%$ Ethanol, 20\% DMSO) maximized the hesperidin concentration, with a value of approximately $0.5 \mathrm{mg} / \mathrm{mL}$. A remarkable difference between Figure 2A $(\mathrm{SSR}=0.1 \mathrm{~g} / \mathrm{mL})$ and Figure $2 \mathrm{~B}$ $(\mathrm{SSR}=0.33 \mathrm{~g} / \mathrm{mL})$ is the effect of the DMSO concentration. At a DMSO content of $0 \%$, the hesperidin concentration remains similar in both figures (approximately $0.3 \mathrm{mg} / \mathrm{mL}$ ). However, at $20 \% \mathrm{DMSO}$ content in the solvent, the hesperidin concentration is greatly increased when the SSR was $0.33 \mathrm{~g} / \mathrm{mL}$, compared to an SSR of $0.1 \mathrm{~g} / \mathrm{mL}$, where the change was subtler. This indicates that when the SSR is 
lower $(0.1 \mathrm{~g} / \mathrm{mL})$, an aqueous solvent with $60 \%$ ethanol is adequate for extracting almost all of the hesperidin. Meanwhile, when the SSR was $0.33 \mathrm{~g} / \mathrm{mL}$, the same solution became saturated, and the addition of $20 \%$ of DMSO increased the ability of the solvent to extract more hesperidin. Finally, the central points displayed a linear response for the hesperidin concentration of the extract.

The extraction yield was calculated as 'mg of hesperidin per gram of fresh peel', and a variance analysis was performed. The results from the analysis of variance (ANOVA) showed that the percent ethanol and SSR significantly affected the extraction yield $(p<0.05)$. The behavior of this response variable is shown in Figure 3. In this figure and in Table 2, it was noted that an SSR of $0.1 \mathrm{~g} / \mathrm{mL}$ and $60 \%$ ethanol maximized the extraction yield, thereby obtaining a value of approximately $3 \mathrm{mg} / \mathrm{g}$. The fact that the extraction yield was lower for higher SSR at 60\% ethanol, confirms that the solvent was becoming saturated. It is also evident that the DMSO percentage by itself did not have an important effect on this variable. Nonetheless, the results from ANOVA suggest that the interaction between the SSR and the DMSO percentage was significant. However, the effect of this interaction is much less evident for the extraction yield than the concentration of hesperidin in the extract. The response of this variable was also linear, as tested with the central points of the experimental design.

A

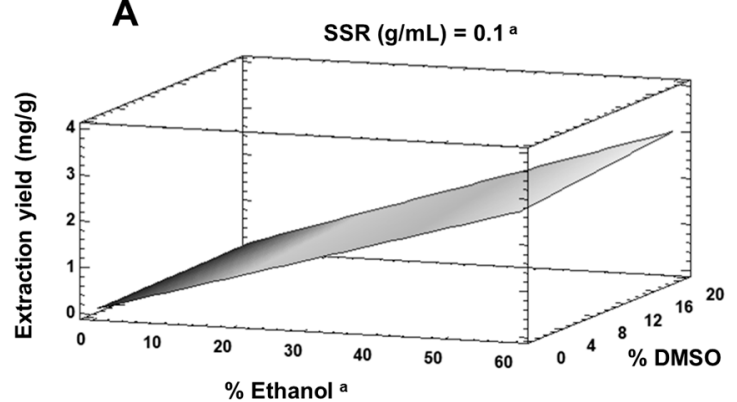

B

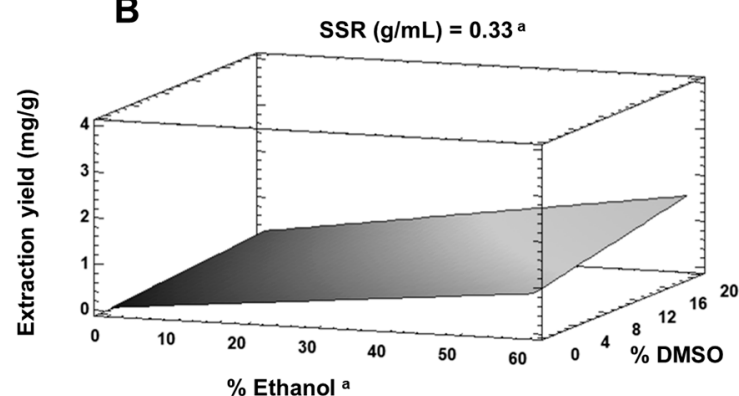

Figure 3. Extraction yield for a solid-to-solvent ratio (SSR) of $0.1 \mathrm{~g} / \mathrm{mL}(\mathbf{A})$ and $0.33 \mathrm{~g} / \mathrm{mL}(\mathbf{B}){ }^{\text {a }}$ Significant factors in the variance analysis $(p<0.05)$.

Table 2. Concentration of hesperidin in the extracts obtained at a laboratory scale.

\begin{tabular}{ccccccc}
\hline Run & $\begin{array}{c}\text { Solid/Solvent } \\
\text { “RSS" (g/mL) }\end{array}$ & \%Ethanol & \%DMSO & Peels $(\mathbf{g})$ & $\begin{array}{c}\text { Hesperidin } \\
\text { Concentration } \\
\text { (mg/mL) }\end{array}$ & $\begin{array}{c}\text { Yield (mg/g } \\
\text { Fresh Peel) }\end{array}$ \\
\hline 1 & 0.215 & 30 & 10 & 10.75 & 0.2191 & 1.019 \\
2 & 0.1 & 0 & 0 & 5 & 0.0220 & 0.220 \\
3 & 0.1 & 0 & 20 & 5 & 0.0354 & 0.354 \\
4 & 0.33 & 60 & 0 & 16.5 & 0.2621 & 0.794 \\
5 & 0.33 & 0 & 0 & 16.5 & 0.0165 & 0.050 \\
6 & 0.33 & 60 & 20 & 16.5 & 0.5752 & 1.743 \\
7 & 0.1 & 60 & 0 & 5 & 0.3410 & 3.410 \\
8 & 0.33 & 0 & 20 & 16.5 & 0.1276 & 0.387 \\
9 & 0.1 & 60 & 20 & 5 & 0.3631 & 3.631 \\
10 & 0.215 & 30 & 10 & 10.75 & 0.2343 & 1.089 \\
11 & 0.215 & 30 & 10 & 10.75 & 0.1814 & 0.843 \\
12 & 0.1 & 0 & 0 & 5 & 0.0000 & 0.000 \\
13 & 0.1 & 0 & 20 & 5 & 0.0000 & 0.000 \\
14 & 0.33 & 60 & 0 & 16.5 & 0.3047 & 0.923 \\
15 & 0.33 & 0 & 0 & 16.5 & 0.0253 & 0.076 \\
16 & 0.33 & 60 & 20 & 16.5 & 0.4866 & 1.474 \\
17 & 0.1 & 60 & 0 & 5 & 0.1994 & 1.994 \\
18 & 0.33 & 0 & 20 & 16.5 & 0.1070 & 0.324 \\
19 & 0.1 & 60 & 20 & 5 & 0.2513 & 2.513 \\
20 & 0.215 & 30 & 10 & 10.75 & 0.1994 & 0.927 \\
\hline
\end{tabular}


These results obtained from the laboratory are of high relevance for the selection of operating conditions at an industrial level. This selection has to be carefully made, and this depends on the objectives and on a cost-benefit analysis. For example, the highest extraction yield possible (if the amount of peel available is limited) could be obtained, despite requiring higher amounts of solvent, which would result in a lower concentration of the extract. On the other hand, lower quantities of solvent can be used on an unlimited peel resource to obtain hesperidin, even though not all of the hesperidin can be collected.

In this particular study, even though the extraction yield was not optimal, we wanted to obtain a higher concentration of hesperidin in the extracts for the adsorption purification step. This step employed the use of an SSR of $0.33 \mathrm{~g} / \mathrm{mL}, 60 \%$ ethanol, and 20\% DMSO. However, the use of DMSO implies its recovery through vacuum evaporation, and it represents an increase in the cost and time of the process. For that reason, we decided to perform the extraction without DMSO, and to use it only before the resin adsorption process, to increase the solubility of hesperidin and to facilitate its adsorption.

\subsubsection{Pilot-Scale Extraction}

The results obtained from the lab-scale extraction step were used in the $20 \mathrm{~L}$ pilot scale extraction, where $6.6 \mathrm{~kg}$ of peel, $12 \mathrm{~L}$ of $96 \%$ ethanol, and $8 \mathrm{~L}$ of deionized water were used. Extract samples were taken every $20 \mathrm{~min}$. Figure 4 shows the mean concentration from the three extractions. It is observed that from 0 to $100 \mathrm{~min}$, the hesperidin concentration increased to a maximum concentration, followed by a slight decreasing trend. The average final concentration was $0.136 \mathrm{~g} / \mathrm{mL}$.

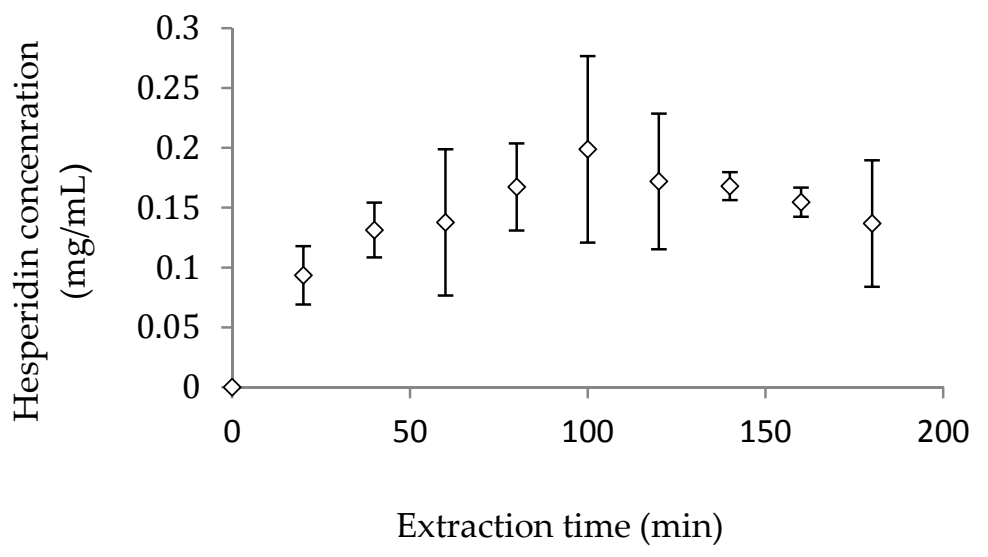

Figure 4. Pilot-scale extraction kinetics.

The efficiency of the hydroalcoholic extraction was $2.25 \mathrm{mg} / \mathrm{g}$ of dry peel. Once the extract was filtered and concentrated, a hesperidin concentration of $0.303 \mathrm{mg} / \mathrm{mL}$ was achieved.

The proposed extraction conditions required a low concentration of alcohol (60\%). To reduce energy consumption, this process was performed at a reduced temperature of $50{ }^{\circ} \mathrm{C}$ for an extraction time of $1 \mathrm{~h}$ and $40 \mathrm{~min}$.

It is very common to use milling and drying (hot air or freeze-drying) as conditioning steps for polyphenol extraction processes [2]. However, freeze-drying is an expensive process, which prevents it from being used at an industrial scale, specially for high water content products such as citrus fruits $[28,29]$. Hot-air drying is cheaper, but it has the disadvantage of exposing the sample to heat and oxygen for extended periods of time [2]. This is why simpler and more economic methods are preferred nowadays.

There are few studies approaching the extraction of bioactive compounds of fresh and untreated citrus wastes, either due to the difficulty of having homogenous particle sizes, or because the water promotes enzymatic reactions. However, if it is processed immediately, this problem is avoided and costs are lowered by eliminating the drying operation and reducing the processing time [30]. Besides, 
the mass transfer in liquid-solid extractions involves the use of dry and ground material, which shortens the extraction time. The particle size can be controlled when fresh material is used, as in the case of polyphenol extraction from oranges, which can controlled by using calibrated steel cubes [30].

Therefore, it is relevant to state that prior drying of the peels was not required in the process proposed in this study, which translated into shorter operation times. This process makes use of fresh peels from the citrus juice industry that exit the pressing operation.

\subsection{Purification}

\subsubsection{Static Tests}

The aqueous extract was diluted with $10 \%$ DMSO, and it reached a hesperidin concentration of $0.272 \mathrm{mg} / \mathrm{mL}$. This extract was used in the static tests.

\section{Adsorption Kinetics}

In order to perform fast adsorption experiments with both resins in further steps, we determined the equilibrium time using a quick method measuring absorbance of total flavonoids. The adsorption kinetics was investigated by allowing the resin to be in contact with the diluted extract for $5 \mathrm{~h}$. In the case of both resins (FPX66 and EXA-118), the concentration decreased rapidly in the first $50 \mathrm{~min}$. As seen in Figure 5, the adsorption kinetics for EXA-118 resin shows that almost all of the flavonoids were adsorbed in this time frame. Regardless, $180 \mathrm{~min}$ was established as an appropriate time to ensure that the adsorption efficiency test reached the equilibrium state. This equilibrium time is in accordance with several works of flavonoid adsorption using resins, where equilibrium times ranging from 60 to $200 \mathrm{~min}$ have been reported [31-34].

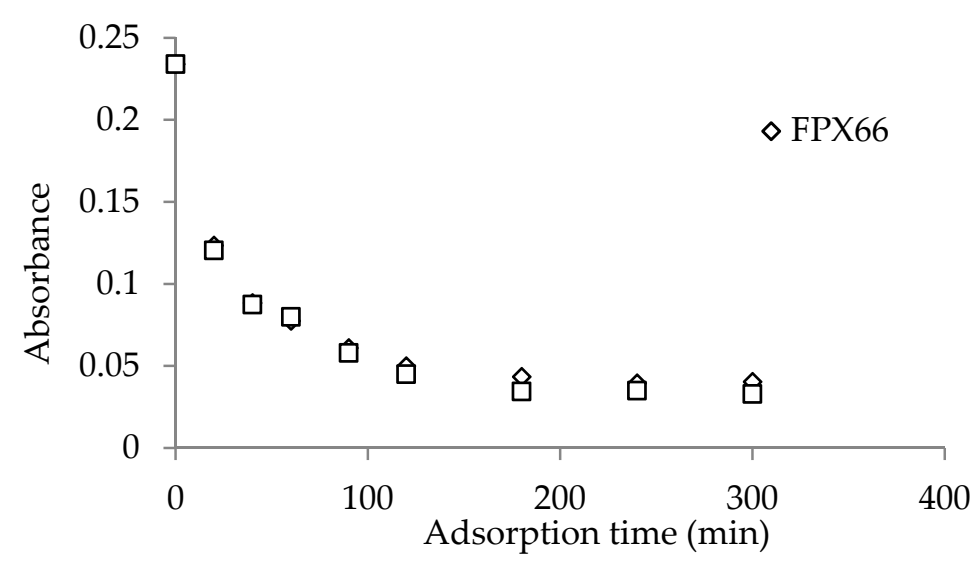

Figure 5. Adsorption kinetics of total flavonoids for EXA-118 and FPX66 resins.

\section{Adsorption Efficiency}

To investigate the effects of the variables (resin, temperature, and initial concentration) for adsorption efficiency, a variance analysis was performed. Six initial concentrations, shown in Table 3, were used. The dilutions were made with a 10\% DMSO solution.

Table 3. Initial concentrations for the adsorption efficiency tests.

\begin{tabular}{cc}
\hline Dilution & Hesperidin Concentration $(\mathrm{mg} / \mathrm{mL})$ \\
\hline 0 & 0.273 \\
1 & 0.218 \\
2 & 0.164 \\
3 & 0.109 \\
4 & 0.054 \\
5 & 0.027 \\
\hline
\end{tabular}


The hesperidin concentration was measured after equilibrium was reached (in approximately $3 \mathrm{~h}$ ). The adsorption efficiency was calculated according to Equation (1):

$$
\varepsilon=\frac{C_{0}-C_{e}}{C_{0}}
$$

where $C_{e}$ is the concentration of hesperidin at equilibrium $(\mathrm{mg} / \mathrm{mL}), C_{0}$ is the initial concentration of hesperidin, and $\varepsilon$ is the efficiency.

The results showed that the type of resin and the initial concentration of the extract have a significant effect over the efficiency $(p<0.05)$. Resin EXA-118 had a higher efficiency, which can be attributed to it having a higher superficial area. Based on the initial concentration, four homogeneous groups were found. On average, dilutions 4 and 5 exhibited higher average adsorption efficiencies.

\subsubsection{Dynamic Tests}

\section{Adsorption}

From the results of the static tests, resin EXA- 118 and $25{ }^{\circ} \mathrm{C}$ temperature, were selected. Dilution 3, with an initial concentration of $0.109 \mathrm{mg} / \mathrm{mL}$, was used in place of dilutions 4 and 5 despite having better efficiencies. This is because in an industrial operation with adsorption columns, the use of dilutions 4 and 5 may result in a higher operation time and higher DMSO requirements.

During the test, $1 \mathrm{~L}$ of diluted extract was passed through the column, and all of the samples taken at the exit of the column did not show peaks in the chromatograms. This led to the conclusion that $100 \%$ of the hesperidin in the extract was adsorbed. This confirmed that the selected dilution was suitable for this operation. A $98 \%$ adsorption from model solutions of hesperidin at $40{ }^{\circ} \mathrm{C}$ has been reported elsewhere [17]. In this work, adding DMSO to the extract helped to achieve an even better adsorption capacity from a more complex mixture, and a temperature of $25^{\circ} \mathrm{C}$, which is an easier temperature to attain in an industrial operation, was proven to be equally useful.

\section{Desorption}

To recover the adsorbed hesperidin, $1 \mathrm{~L}$ of $96 \%$ ethanol was passed through the column. Only the four first-collected fractions (50 mL each) at the exit of the column showed peaks during the chromatographic analysis. As a result, it took only $200 \mathrm{~mL}$ of ethanol to desorb and recover the hesperidin from a $1 \mathrm{~L}$ sample of extract, which had an initial concentration of $0.109 \mathrm{mg} / \mathrm{mL}$. Figure 6 shows the recovery efficiency ( $\mathrm{mg}$ of hesperidin recovered/mg of hesperidin adsorbed) that was achieved, based on the volume eluted from the column.

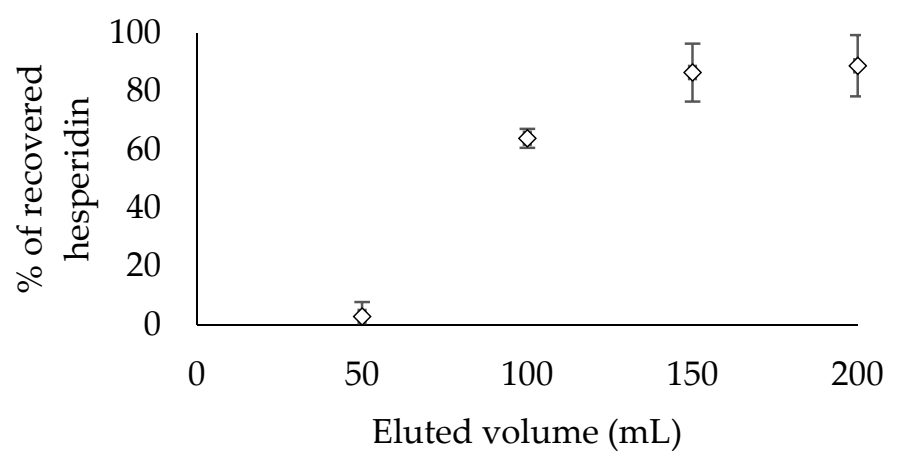

Figure 6. Hesperidin recovery efficiency during desorption.

The average recovery efficiency was almost $90 \%$, and approximately $68 \%$ of the recovered hesperidin was in the first $100 \mathrm{~mL}$ that exited the column. The hesperidin concentration in the $200 \mathrm{~mL}$ that left the column was almost five times higher than the initial concentration of the extract, representing a good efficiency of purification. 
It has been reported that the extraction of hesperidin is possible, due to a conformation change of hesperidin to its anionic form (anion polyphenolate) at basic $\mathrm{pH}$ conditions [16]. The effect of the amount of $\mathrm{Ca}(\mathrm{OH})_{2}$ over the extraction efficiency of hesperidin from orange peel has been previously studied, where the extracts were purified with the resin Kastell S-112, obtaining recoveries above $90 \%$, using $0.5 \mathrm{~N} \mathrm{NaOH}$ and $10 \%$ ethanol solutions, and recovering most of the hesperidin in the first $100 \mathrm{~mL}$ [16]. In this work, it was possible to purify hesperidin with a similar high efficiency without the addition of $\mathrm{Ca}(\mathrm{OH})_{2}$ or $\mathrm{NaOH}$, showing that the separation of hesperidin is possible in acid conditions, with a process that reduces the economic and ecologic cost of the traditional alkaline treatment and that only uses solvents that can be recovered and reused. However, since all of the hesperidin was absorbed, there is still opportunity to improve the $90 \%$ recovery efficiency that was attained in this work. This could be achieved by evaluating other desorption conditions, such as other solvents or mixtures of solvents, flow, temperature, etc.

Also, it is important to state that most of the literature about the extraction and purification of bioactive compounds are focused on orange (Citrus sinensis), lemon (Citrus limon), grapefruit (Citrus paradisi), and mandarin (Citrus reticulata), and there are very few studies nowadays that are focused on studying Mexican lime (Citrus aurantifolia Swingle) which is an important citrus fruit worldwide.

Finally, Figure 7 shows the general conditions of the method proposed in this work to extract and purify hesperidin from Mexican lime peel, and this could be extended to other citrus fruit.

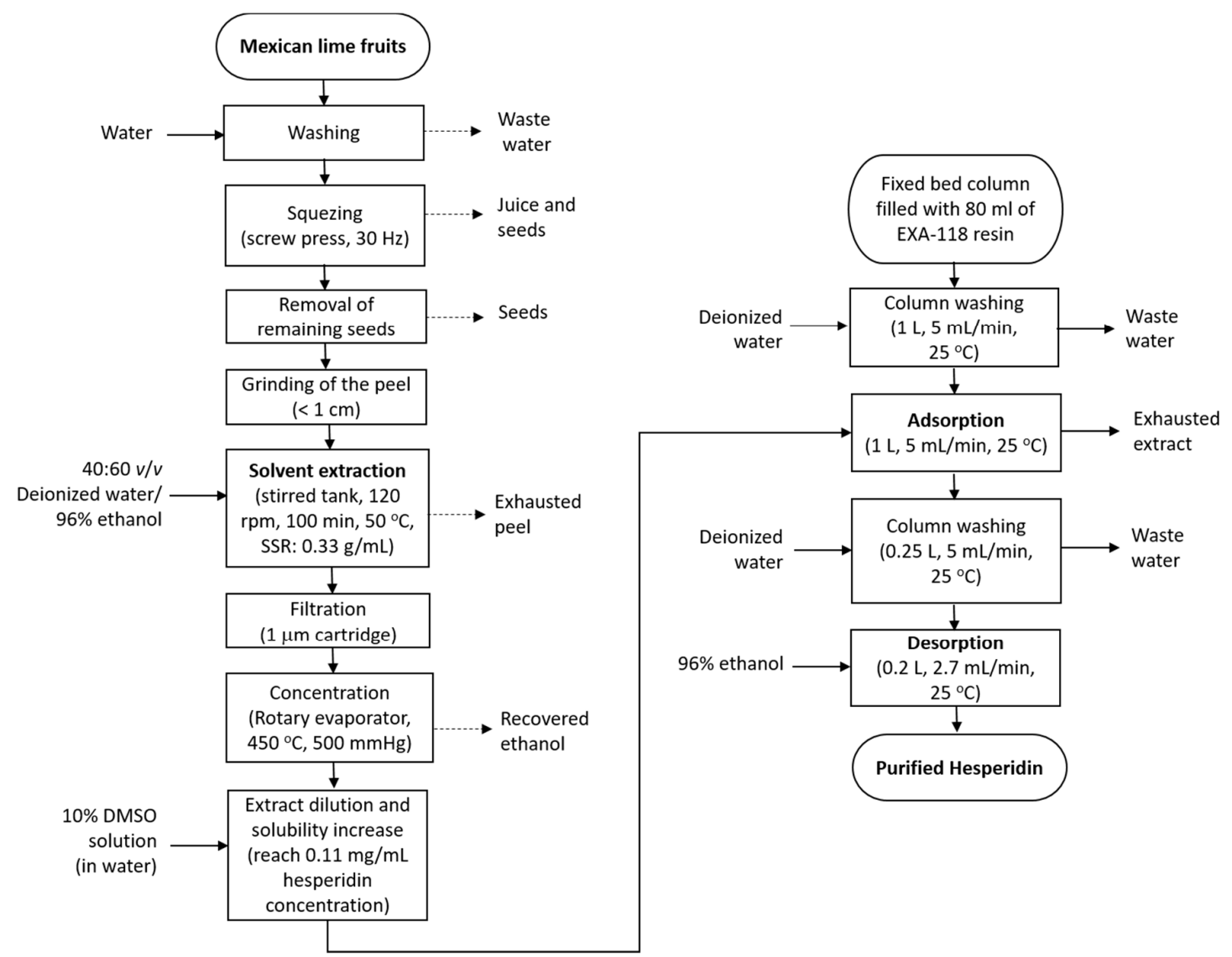

Figure 7. Proposed method by the authors, for the extraction and purification of hesperidin from Mexican lime peel.

\section{Conclusions}

The purification process of hesperidin from Mexican lime peel, comprising a hydroalcoholic extraction and purification using a packed bed with resin EXA-118, presents advantages over the 
traditional alkaline process, since it does not require the use of acids and bases, which represent an important environmental and economic cost. Also, it has similar or higher recovery efficiencies than the reported alkaline methods. Therefore, this process offers an excellent alternative for its implementation on an industrial scale as a green technology for the recovery of hesperidin from citrus peel. Based on the reduced number of unit operations (extraction, evaporation, filtration, adsorption, and desorption), this process has been characterized for its simplicity and economic advantages.

Author Contributions: Conceptualization, J.D.P.d.1.R., G.M.G.-M. and E.A.-G.; Formal analysis, J.D.P.d.1.R., P.R.-P. and E.A.-G.; Investigation, J.D.P.d.1.R., P.R.-P., G.M.G.-M., J.A.G.-F. and G.C.S.-F.; Methodology, J.D.P.d.1.R, P.R.-P. and J.A.G.-F.; Project administration, J.A.G.-F.; Resources, G.C.S.-F. and E.A.-G.; Supervision, E.A.-G.; Validation, P.R.-P.; Visualization, G.C.S.-F.; Writing—original draft, J.D.P.d.1.R, P.R.-P., J.A.G.-F. and G.C.S.-F.; Writing—review \& editing, G.M.G.-M. and E.A.-G.

Funding: This research was funded by CONACYT, grant number 307640, the Centro de Investigación y Asistencia en Tecnología y Diseño del Estado de Jalisco, A.C. (CIATEJ), and the Universidad de Guadalajara (UDG).

Acknowledgments: The authors would like to thank CONACYT for scholarship No. 249191 and project CB- 237737.

Conflicts of Interest: The authors declare no conflict of interest.

\section{References}

1. FAOSTAT (2016). Food and Agricultural Organization of the United Nations. Statistics Division. Available online: http:/ / www.fao.org/faostat/en/\#data/QC (accessed on 1 December 2018).

2. Ledesma-Escobar, C.A.; Luque de Castro, M.D. Towards a comprehensive exploitation of citrus. Trends Food Sci. Technol. 2014, 39, 63-75. [CrossRef]

3. Londoño-Londoño, J.; De Lima, V.R.; Lara, O.; Gil, A.; Pasa, T.B.C.; Arango, G.J.; Pineda, J.R.R. Clean recovery of antioxidant flavonoids from citrus peel: Optimizing an aqueous ultrasound-assisted extraction method. Food Chem. 2010, 119, 81-87. [CrossRef]

4. Nogata, Y.; Sakamoto, K.; Shiratsuchi, H.; Ishii, T.; Yano, M.; Ohta, H. Flavonoid composition of fruit tissues of citrus species. Biosci. Biotechnol. Biochem. 2006, 70, 178-192. [CrossRef] [PubMed]

5. Güemez, F.J.; Zapata, J.L.; González, E.; Kú, M.; Lechuga, P.; Salinas, A. Potencialidades del mercado nacional e internacional de la hesperidina de origen natural obtenida de la naranja como sustituto de antioxidantes químicos en la industria alimentaria. In Proceedings of the $5^{\circ}$ Congreso Internacional de Sistemas de Innovación para la Competitividad, Celaya, México, 25-27 August 2010; pp. 1-22.

6. Galati, E.M.; Monforte, M.T.; Kirjavainen, S.; Forestieri, A.M.; Trovato, A.; Tripodo, M.M. Biological effects of hesperidin, a citrus flavonoid. (Note I): Antiinflammatory and analgesic activity. Farmaco 1994, 40, 709-712. [PubMed]

7. Bok, S.H.; Lee, S.H.; Park, Y.B.; Bae, K.H.; Son, K.H.; Jeong, T.S.; Choi, M.S. Plasma and hepatic cholesterol and hepatic activities of 3-hydroxy-3-methyl-glutaryl-CoA reductase and acyl CoA: cholesterol transferase are lower in rats fed citrus peel extract or a mixture of citrus bioflavonoids. J. Nutr. 1999, 129, 1182-1185. [CrossRef] [PubMed]

8. Galati, E.M.; Kirjavainen, S.; Forestieri, A.M.; Rossitto, A.; Monforte, M.T. Biological effects of hesperidin, a Citrus flavonoid. (Note III): antihypertensive and diuretic activity in rat. Farmaco. 1996, 51, 219-221. [PubMed]

9. Raza, S.S.; Khan, M.M.; Ahmad, A.; Ashafaq, M.; Khuwaja, G.; Tabassum, R.; Javed, H.; Siddiqui, M.S.; Safhi, M.M.; Islam, F. Hesperidin ameliorates functional and histological outcome and reduces neuroinflammation in experimental stroke. Brain Res. 2011, 1420, 93-105. [CrossRef]

10. Chen, M.C.; Ye, Y.Y.; Guang, J.I.; Jian-Wen, L.I.U. Hesperidin upregulates heme oxygenase-1 to attenuate hydrogen peroxide-induced cell damage in hepatic L02 cells. J. Agric. Food Chem. 2010, 58, 3330-3335. [CrossRef]

11. Dugo, G.; Di Giacomo, A. Citrus: The genus Citrus, 1st ed.; Taylor \& Francis: London, UK, 2002; pp. 169-170. ISBN 0415-28491-0.

12. De Oliveira, R.C.; Davantel De Barros, S.T.; Gimenes, M.L. The extraction of passion fruit oil with green solvents. J. Food Eng. 2013, 117, 458-463. [CrossRef]

13. Li, B.B.; Smith, B.; Hossain, M.M. Extraction of phenolics from citrus peels. Sep. Purif. Technol. 2006, 48, 182-188. [CrossRef] 
14. Capello, C.; Fischer, U.; Hungerbühler, K. What is a green solvent? A comprehensive framework for the environmental assessment of solvents. Green Chem. 2007, 9, 927-934. [CrossRef]

15. Di Mauro, A.; Fallico, B.; Passerini, A.; Maccarone, E. Waste water from citrus processing as a source of hesperidin by concentration on styrene-divinylbenzene resin. J. Agric. Food Chem. 2000, 48, 2291-2295. [CrossRef] [PubMed]

16. Di Mauro, A.; Fallico, B.; Passerini, A.; Rapisarda, P.; Maccarone, E. Recovery of hesperidin from orange peel by concentration of extracts on styrene-divinylbenzene resin. J. Agric. Food Chem. 1999, 47, 4391-4397. [CrossRef] [PubMed]

17. Scordino, M.; Di Mauro, A.; Passerini, A.; Maccarone, E. Adsorption of flavonoids on resins: Hesperidin. J. Agric. Food Chem. 2003, 51, 6998-7004. [CrossRef] [PubMed]

18. Gutiérrez, V.L. Extracción y caracterización de flavonoides contenidos en limón persa (Citrus Latifolia Tanaka) en un proceso a nivel piloto. Bachelor's Thesis, Universidad de Guadalajara, Guadalajara, Mexico, 2009.

19. Velásquez, M.N. Extracción y purificación de hesperidina a partir de cáscara de limón persa. Bachelor's Thesis, Instituto Tecnológico de Durango, Durango, Mexico, 2010.

20. Londoño, J.; Sierra, J. Efecto de la hesperidina sobre la captacion de hdl en células hepáticas y evaluacion de hesperidina liposomal sobre la oxidacion de LDL. Sci. Tec. 2007, 8, 63-66. [CrossRef]

21. Selleckchem: Hesperidin. Available online: http://www.selleckchem.com/products/Hesperidin.html (accessed on 15 October 2016).

22. Soroko, I.; Bhole, Y.; Livingston, A.G. Environmentally friendly route for the preparation of solvent resistant polyimide nanofiltration membranes. Green Chem. 2011, 13, 162-168. [CrossRef]

23. McKim, A.S.; Strub, R. Dimethyl Sulfoxide USP, PhEur in Approved Pharmaceutical Products and Medical Devices. Pharm. Technol. 2008, 32, 74-85.

24. Zhishen, J.; Mengcheng, T.; Jianming, W. The determination of flavonoid contents in mulberry and their scavenging effects on superoxide radicals. Food Chem. 1999, 64, 555-559. [CrossRef]

25. Escobar, M.; Hernández, H.Y.; Barragán, B.E. Extracción de compuestos fenólicos de cáscaras de cítricos producidos en México (Naranja valencia, Naranja agria, Limon mexicano, Limon real, Mandarina, Toronja y Lima). In XVII Congreso Nacional de Ingenieria Bioquímica; Colegio Mexicano de Ingenieros Bioquímicos: Acapulco, México, 2010.

26. Andersen, O.M.; Markham, K.R. Flavonoids: Chemistry, Biochemistry and Applications, 1st ed.; Taylor \& Francis: Boca Raton, FL, USA, 2006; pp. 923-924. ISBN 9780849320217.

27. Ladaniya, M.S. Citrus Fruit. Biology, Technology and Evaluation, 1st ed.; Academic Press: San Diego, CA, USA, 2008; ISBN 9780080556239.

28. Berk, Z. Freeze drying (Lyophilization) and freeze concentration. In Food process engineering and technology, 2nd ed.; Academic Press: San Diego, CA, USA, 2013.

29. Kasper, J.C.; Winter, G.; Friess, W. Recent advances and further challenges in lyophilization. Eur. J. Pharm. Biopharm. 2013, 85, 162-169. [CrossRef]

30. Khan, M.K.; Abert-Vian, M.; Fabiano-Tixier, A.S.; Dangles, O.; Chemat, F. Ultrasound-assisted extraction of polyphenols (flavanone glycosides) from orange (Citrus sinensis L.) peel. Food Chem. 2010, 119, 851-858. [CrossRef]

31. Scordino, M.; Di Mauro, A.; Passerini, A.; Maccarone, E. Highly purified sugar concentrate from a residue of citrus pigments recovery process. LWT-Food Sci. Technol. 2007, 40, 713-721. [CrossRef]

32. Silva, E.; Pompeu, D.; Larondelle, Y.; Rogez, H. Optimisation of the adsorption of polyphenols from Inga edulis leaves on macroporous resins using an experimental design methodology. Sep. Purif. Technol. 2007, 53, 274-280. [CrossRef]

33. Zhang, Y.; Li, S.; Wu, X.; Zhao, X. Macroporous Resin Adsorption for Purification of Flavonoids in Houttuynia cordata Thunb. Chin. J. Chem. Eng. 2007, 15, 872-876. [CrossRef]

34. Zhao, Z.; Dong, L.; Wu, Y.; Lin, F. Preliminary separation and purification of rutin and quercetin from Euonymus alatus (Thunb.) Siebold extracts by macroporous resins. Food Bioprod. Process. 2011, 89, $266-272$. [CrossRef]

(C) 2018 by the authors. Licensee MDPI, Basel, Switzerland. This article is an open access article distributed under the terms and conditions of the Creative Commons Attribution (CC BY) license (http:/ / creativecommons.org/licenses/by/4.0/). 